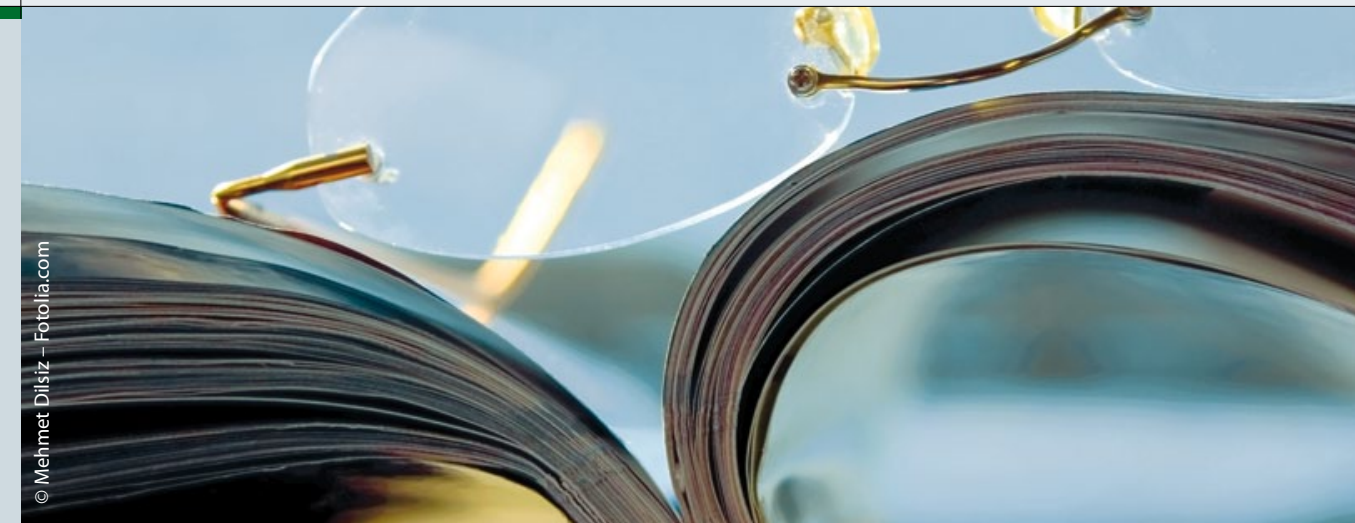

\section{Einheitslänge von Spermien verspricht gute Fertilität}

Die Qualität von Sperma hängt offenbar nicht nur von der Morphologie, also der Größe und Form der Spermien ab, sondern auch von der Länge einzelner Spermiumkomponenten. Je größer die Variabilität dieser Parameter im Ejakulat ist, umso kleiner ist der Anteil der beweglichen Spermien und umso geringer ist die Fertilität.

W enn es um die Beurteilung der Spermaqualität geht, konzentrierte man sich bisher vor allem auf die Morphologie des Spermatozoenkopfes und auf die Gesamtgröße. Erstmals haben sich jetzt Reproduktionsmediziner aus Großbritannien und den USA die Spermatozoen genauer angeschaut und den Kopf, das Mitochondrien enthaltende Mittelstück und das Flagellum im Detail ver- messen. Dann setzten sie die ermittelten Daten in Beziehung zu den Ergebnissen der computergestützten Spermienanalyse (CASA). Untersucht wurde jeweils ein Ejakulat von insgesamt 103 Studienteilnehmern. Vermessen wurden pro Studienteilnehmer jeweils 30 Samenzellen.

Wie aus den Messungen zum einen hervorgeht, sind eine große Spermienmenge im Ejakulat, eine hohe Zahl be-



Spermiogramme könnten künftig durch Daten einer exakten Vermessung der Spermatozoen ergänzt werden.

weglicher Spermien und ein hoher Anteil jener Spermien, die im Spermiogramm den WHO-Kategorien A und B zugeordnet werden können - also langsam oder schnell vorwärts beweglich sind -, offenbar mit einer erhöhten Wahrscheinlichkeit für das Vorhandensein von Spermien assoziiert, die mit langen Flagellen ausgestattet sind und insgesamt besonders lang sind. Das Flagellum macht etwa 90\% der Gesamtlänge eines Spermiums aus. Zum anderen stellte sich heraus, dass bei einer geringen Variation in der Spermiengesamtlänge eines Ejakulats die Wahrscheinlichkeit für das Vorhandensein beweglicher Spermien hoch ist, und zwar solcher Zellen, die mindestens $5 \mu \mathrm{m} / \mathrm{s}$ schnell schwimmen (WHO A + B). Allerdings gab es keinen Zusammenhang zwischen Gesamtlänge und Variation in der Länge der Spermienkomponenten sowie den Ergebnissen der CASA-Analyse.

Fazit: Es gibt einen Zusammenhang zwischen Gesamt- und Flagellumlänge und der Spermaqualität. Die Autoren vermuten, dass die Parameter einen Hinweis auf die Funktion der Sertolizellen liefern, die sich bisher nur mit sehr invasiven Verfahren bestimmen lässt. Die intakte Funktion der Sertolizellen ist Voraussetzung für die erfolgreiche Spermienentwicklung auch am Ende der Spermatogenese. Je größer der Hoden und damit wahrscheinlich auch je größer die Sertolizellen, desto länger sind nach Angaben der Autoren die Spermien innerhalb eines Ejakulats. Peter Leiner

Mossman J et al. Variation in mean human sperm length is linked with semen characteristics. Hum Reprod 2013; 28: 22-32 